\title{
¿TERMINA O SE TRANSFORMA? \\ UN SIGLO DE SECULARIZACIÓN Y RELIGAMIENTO DEL CERRO DE LOS ÁNGELES A EL ROCÍO
}

\author{
Santiago Navarro de la Fuente* \\ Universidad de SeVilla
}

\begin{abstract}
RESUMEN
En el año 2019 se han celebrado, con escasa diferencia temporal, pero con muy diferentes magnitudes institucionales y populares, sendos centenarios de cierta relevancia para el catolicismo español contemporáneo. Estas efemérides nos han ofrecido una ocasión para analizar los cambios y continuidades habidos en el comportamiento religioso de los españoles en la centuria que media entre el 30 de mayo de 1919 en que Alfonso XIII consagró España al Sagrado Corazón de Jesús y el 8 de junio de 2019 en que se cumplieron cien años de la coronación canónica de la imagen de la Virgen del Rocío, patrona de Almonte. Al hacerlo, nos proponemos reflexionar, mediante el análisis historiográfico de estos casos concretos, sobre la idoneidad de algunos conceptos propios de la sociología para el estudio de la historia cultural de la religión.
\end{abstract}

PALABRAS CLAVE: secularización, historia cultural de la religión, religamiento, Sagrado Corazón, Virgen del Rocío

Enviado: 15-11-2019

Aceptado: $30-1-2020$

*snav@us.es 


\title{
AN END OR A CHANGE? \\ A CENTURY OF SECULARIZATION AND RE-LIGAMENT. FROM CERRO DE LOS ANGELES HILLS TO EL ROCIO TOWN
}

\author{
Santiago Navarro de la Fuente* \\ Universidad de Sevilla
}

\begin{abstract}
Two different centenary anniversaries, quite significant for contemporary Roman Catholicism, have been celebrated in 2019 very close in time. They had anyway different impact in both public institutions and the population. These events triggered an investigation about the changes and the settings of the religious behavior of Spaniards between May, 30th 1919, when King Alfonso XIII of Spain consecrated the country to the Sacred Heart of Jesus, and June, 8th 2019, when it took place the centennial anniversary of the canonical coronation of the holy sculpture of the Madonna of El Rocio, the patron saint of Almonte city. In our research, we will analyze the historiography of these two cases by linking some concepts of sociology with the cultural study of religion.
\end{abstract}

KEYWORDS: secularization, cultural history of religion, re-ligament, Sacred Heart, Madonna of El Rocio

*snav@us.es 


\section{INTRODUCCIÓN}

En 1919, con pocos días de diferencia, tuvieron lugar la consagración de España al Sagrado Corazón de Jesús y la coronación canónica de la imagen mariana de la Virgen del Rocío, patrona de Almonte. La celebración del centenario de ambos acontecimientos ofrece una ocasión propicia para comparar la situación ambas devociones tanto en la actualidad como hace cien años. El tiempo transcurrido y los cambios habidos en ellas, objeto de interés para una historia cultural de lo religioso, nos permiten también abordar desde un punto de vista historiográfico la utilidad de algunos conceptos propios de la sociología, como los de "secularización" y "religamiento", y también plantear algunas propuestas sobre los mecanismos para una "recomposición" de lo religioso en la modernidad.

\section{DOS DEVOCIONES UN SIGLO DESPUÉS}

El día después de la inauguración del monumento al Sagrado Corazón en el Cerro de los Ángeles y de la consagración de España, el diario católico sevillano El Correo de Andalucía reproducía a lo largo de sus apenas cuatro páginas de edición la fórmula que había pronunciado Alfonso XIII para consagrar el país al Corazón Divino mientras los asistentes se postraban arrodillados ante el Santísimo expuesto en manifiesto:

... España, pueblo de tu herencia y de tus predilecciones, póstrase reverente ante este trono de tus bondades que para ti se alza en el centro de la península.- Todas las razas que la habitan, todas las regiones que la integran, que han constituido en la sucesión de los siglos y a través de múltiples azares, la gran Patria española, en fuerte y constante amor a la Religión y adhesión a la Monarquía, y yo, sintiendo la tradición católica de la realeza española y continuando gustoso la historia de fe y devoción a Vuestra Divina Persona, confesamos que vinisteis a la tierra a establecer el reino de Dios y conceder la paz a las almas redimidas por Vuestra Sangre y la dicha a los pueblos que se rijan por vuestra Santa Ley y reconocemos que tenéis como blasón de Vuestra Divinidad conceder participación del Poder Vuestro a los Príncipes de la tierra y que de Vos necesitan sanción las leyes justas, en cuyo cumplimiento estriba el imperio del orden y la paz, que son camino seguro que conduce a la vida eterna, luz inextinguible que alumbra el entendimiento para que conozca la verdad y principio propulsor de toda vida y de todo legítimo progreso social, y encontrándose en Vos y en el poderío y suavidad de vuestra Gracia todas las virtudes y heroísmos elevan y hermosean el alma.- Venga, pues, a nosotros tu santísimo Reino, que es 
Reino de justicia y de amor. Reinad en los corazones de los hombres, en el seno de los hogares, en la inteligencia de los sabios, en las aulas de las ciencias y de las letras y en nuestras leyes e instituciones Patrias.- Gracias, Señor, por habernos librado de la común desgracia de la guerra. Continuad con nosotros la obra de vuestra amorosa Providencia desde estas alturas que para Vos hemos escogido como símbolo de los deseos que nos animan de que presidáis todas nuestras empresas. Bendecid a los pobres obreros proletarios y haced que para la pacífica armonía de las clases sociales encuentren la justicia y la caridad que les hagan más suave su vida, más llevadero su trabajo.- Bendecid al Ejército y la Marina para que la lealtad, disciplina y valor de sus armas sean siempre salvaguarda de la nación y del derecho.- Bendecidnos a todos los aquí reunidos en la cordialidad de los mismos santos amores de la Religión y de la Patria.- Queremos consagrar a Vos nuestras vidas pidiéndoos como premio por ellas el morir en la seguridad de Vuestro amor y en el regalado seno de vuestro Corazón adorable ${ }^{1}$.

La vinculación de la fe religiosa con la adhesión monárquica que inflamaba el texto se reflejaba también en el modo en que el rey pretendía el sometimiento de todas las realidades del país a los preceptos de Jesucristo, ya fuera en el orden político o en el social. Respondía ello al concepto de "reinado social" de Jesucristo que desde el siglo XIX se había venido vinculando con la devoción al Sagrado Corazón. De hecho, las consagraciones "constituían una respuesta al laicismo" y una "forma de apoyar la idea de una opción política que tuviera en cuenta el mensaje evangélico a la hora de organizar la vida social"'.

Esa era también la percepción en las glosas con las que la prensa vinculada con la jerarquía de la Iglesia celebró el acontecimiento. Así, en el diario propiedad del prelado sevillano, Rafael Sánchez Arraiz interpretó en clave de tradición patriótica que

... el Lábaro Santo ondeará en el Cerro de los Ángeles y recibirá el poderoso aliento de Pelayo y Recaredo, de Alonso el Sabio y Fernando el Santo, de Guzmán el Bueno y Hernán Cortés, de Cisneros y Juan de Austria y de cuántos héroes, santos y sabios lucharon y trabajaron en España por la Patria y la Religión ${ }^{3}$.

1. Transcripción de la fórmula de consagración (31-V-1919), El Correo de Andalucía. Sin diferencias sustanciales con la transcripción de L. CANO (2009), 88-89.

2. L. CANO (2009), 39-42, 48.

3. R. SÁnchez Arráiz (31-V-1919), El Correo de Andalucía. 
Para terminar sus letras pidiendo que "desde todo lugar donde haya un alma española, se eleve ardiente y fervorosa siquiera una corta oración: -Dios mío, Sagrado Corazón de Jesús, salvad a España"4.

La difusión que la prensa católica hacía de la consagración repetía esta doble insistencia de Sánchez Arraiz. De un lado, miraba a las glorias nacionales con el deseo de que la consagración provocase un renovado impulso religioso a imagen del que estaban convencidos que había vivido España en el pasado. De otro, miraban el presente de la Iglesia con una conciencia de vulnerabilidad ante la evolución del país en el momento, que consideraban socialmente cada vez más alejado de la fe cristiana. Esta dimensión, en realidad, era consecuencia lógica del componente expiatorio y de reparación que caracterizaba la devoción "corazonista" desde las revelaciones místicas a Santa Margarita María de Alacoque (1647-1690). Una dimensión que no conviene olvidar por cuanto se refería a la necesidad de la "conversión de los pecadores, de los tibios, de los indiferentes o de los díscolos y disidentes" en el mundo del Antiguo Régimen ${ }^{5}$.

A los pocos días se celebró el domingo de Pentecostés de aquel año. Fue el 8 de junio de 1919. Ese día el cardenal Almaraz y Santos, arzobispo de Sevilla, coronó canónicamente la imagen de la Virgen del Rocío, patrona de Almonte (Huelva), en el entorno de su ermita en la "solitaria marisma" onubense. El acontecimiento, a pesar de las limitaciones del momento para acceder al lugar en que se veneraba la imagen, contó con la presencia de las primeras once hermandades filiales, además de la matriz de Almonte, y se caracterizó por una amplia difusión en la prensa del momento. Un análisis del El Correo de Andalucía entre finales de mayo y mediados de junio revela, sin duda, un mayor tratamiento de la celebración mariana que de la consagración de España al Sagrado Corazón ${ }^{6}$.

A la vuelta de un siglo, el centenario de aquellos acontecimientos nos ofrece la ocasión de comparar la evolución de ambas devociones y su incidencia en el catolicismo español de nuestros días. De un lado, el aniversario de la consagración de España al Sagrado Corazón ha revestido un modo de

4. R. Sánchez Arráiz (31-V-1919), El Correo de Andalucía.

5. L. Cano (2009), 39-35, 50.

6. En este sentido, el periódico llevó a su portada noticias y crónicas relativas a la coronación de la imagen y a la romería desde el viernes 6 de junio hasta el domingo 15 , (6 a 15-VI-1919), El Correo de Andalucía. Se trata de un seguimiento que también puede rastrearse en los meses previos. 
celebración muy diferente en el tono del que caracterizó el hecho primero. El lugar era el mismo, el reconstruido monumento al Sagrado Corazón que fue edificado tras la destrucción del original durante la Guerra Civil. La fecha era similar, el 30 de junio de 2019; pero muchas cosas habían cambiado. No estuvo el rey. Su ausencia la explicó el portavoz de los obispos, Luis Argüello, indicando que "tiene un papel constitucional distinto" al de su bisabuelo. Y, aunque no había autoridad alguna que representase al país constituido civilmente, sí hubo algunas personalidades militares. Así se daba forma a la pretensión del obispo diocesano de hacer de la renovación "un acto religioso, no político". El prelado de Getafe había escrito: "entendemos, por tanto, la renovación de la consagración como una manifestación de piedad, desvinculada de cualquier lectura política o de nostalgias de épocas pasadas"7. Esta vocación de redefinir el gesto celebrado un siglo antes se apreció en que el agente de la consagración había dejado de ser "España" y habían pasado a ser "los católicos españoles". A las diez de la mañana, ante una multitud de unas diez mil personas, el cardenal arzobispo de Madrid Carlos Osoro, el obispo de Getafe Ginés García junto a otros dieciocho obispos y más de un centenar de sacerdotes celebraron la misa, que estuvo presidida por la imagen de la Virgen de los Ángeles, patrona de Getafe. A su término realizaron la renovación de la consagración a partir de una fórmula que recordaba a la empleada hacía un siglo, pero con sustanciales cambios ${ }^{8}$.

En la "oración de renovación de la consagración de España al Sagrado Corazón de Jesús" desaparecieron las referencias a las "razas" y "regiones" de España, como también desaparecieron las alusiones a la patria y a la monarquía. El afán de regirse por la "santa ley" y la participación de las autoridades en el poder divino que habían inflamado el texto original, se sustituyeron por "el amor que has revelado a través de tu Sagrado Corazón". Con la renovación, la pretensión no era ya ordenar el país conforme a las disposiciones divinas tal como había formulado Alfonso XIII, sino que "los fieles católicos expresamos nuestro ferviente deseo de corresponder con amor a la rica efusión de tu misericordia". De esta forma, actuando a través de la correspondencia de los fieles al amor divino, se aspiraba -como en la fórmula original- a que el Sagrado Corazón "reinara en los corazones de los hombres, en el seno de los hogares, en la inteligencia de los sabios, en las aulas de las ciencias y de las letras y en nuestras leyes e instituciones".

7. G. García Beltrán (2019), 9.

8. M. SÁnchez GonzÁlez (2019). 
Finalmente, desaparecieron las peticiones de bendición para el ejército y la marina y se incorporaron dos párrafos referidos a la Virgen María, que no había aparecido en el texto original ${ }^{9}$.

La Santa Sede participó también del centenario de la consagración concediendo un año jubilar con tal motivo a la diócesis de Getafe y elevando a la condición de Basílica Menor el santuario. También al santuario de la Virgen del Rocío, en Almonte, concedió la Santa Sede un año jubilar con motivo del centenario de la coronación canónica de imagen, aunque sin modificar la condición del templo en que se venera la talla mariana de tan singular devoción.

La celebración propia del centenario de la coronación canónica del sagrado simulacro ha estado, en realidad, extendida en diversos acontecimientos de carácter extraordinario y también ordinarios, pero dotados de una relevancia particular. El acto central de la celebración de la efeméride tuvo lugar el 8 de junio de 2019. Ese día, que coincidía con el sábado de la popular romería de Pentecostés, tuvo lugar la apertura del año jubilar concedido por la Santa Sede y la celebración de una eucaristía de acción de gracias presidida por el arzobispo de Sevilla D. Juan José Asenjo, sucesor del cardenal Almaraz en la sede hispalense ${ }^{10}$, y concelebrada por distintos obispos y sacerdotes.

Aquella celebración pasó como uno más de los actos de la multitudinaria romería de Pentecostés. Cada año, esta fiesta religiosa y popular en torno a la Virgen marismeña congrega a un número de asistentes que ha ido superándose progresivamente ${ }^{11}$. Así, frente a las once hermandades filiales que asistieron a la coronación de 1919, han sido 124 las que han acudido a la romería cien años después ${ }^{12}$ lo que habla de un crecimiento

9. V. C. Bustillo (2019).

10. A pesar de que, en la actualidad, la localidad de Almonte pertenece a la diócesis de Huelva, la celebración del centenario fue presidida por el arzobispo de Sevilla en memoria de que fue su antecesor quien coronó a la Virgen del Rocío en 1919, cuando la provincia de Huelva pertenecía a la archidiócesis de Sevilla. M. Á. JimÉnez (9-VI-2019), $A B C$.

11. La década de los ochenta del siglo XX supuso una verdadera revolución en el número de asistentes a la romería, que superó el millón de personas en 1980 y alcanzó el millón y medio en 1985. M. D. Murphy y C. González Faraco (2002), 96, tabla 1.

12. A las 124 deben unirse otras 40 hermandades de toda la geografía española que no tienen aún la condición de filiales y otras cuatro establecidas fuera de España (en Venezuela y Argentina). No incluimos la referencia a las asociaciones que no tienen la erección canónica como asociación pública de fieles. Datos de la Hermandad matriz de Almonte: URL: https://hermandadmatrizrocio.org/hermandades-filiales/ (consulta: 17-10-2019). 
exponencial de la devoción popular por el icono almonteño, que lo convierte en un fenómeno singular ${ }^{13}$. Bien es cierto que, en las últimas décadas, la romería ha proyectado la imagen de una fiesta a menudo alejada del espíritu religioso, recibiendo frecuentemente críticas por el ambiente festivo y el comportamiento poco edificante de muchos de sus asistentes, situándola a veces antes como una fiesta folclórica y popular que como una manifestación de fervor religioso ${ }^{14}$.

La celebración del centenario, sin embargo, había comenzado el 8 de septiembre anterior con una procesión extraordinaria de la imagen de la Virgen del Rocío por el entorno de su ermita. Una procesión a la que no concurrieron las hermandades filiales, ni tuvo lugar en el tradicional ambiente festivo de Pentecostés, a pesar de lo cual congregó en torno a medio millón de personas según el Plan Municipal de Emergencias de Almonte ${ }^{15}$. El centenario de la coronación ha venido a coincidir también con el rito de traslado de la imagen al núcleo urbano del municipio del que es patrona. En el siglo XX quedó instituido que la imagen de la Virgen del Rocío fuera trasladada a la parroquia de la Asunción del pueblo cada siete años, permaneciendo en el céntrico templo de la localidad entre los meses de agosto y la siguiente romería de Pentecostés. Este traslado se caracteriza por hacerse en las horas de la noche del estío, saliendo la imagen de la aldea donde se encuentra habitualmente a la puesta de sol del 19 de agosto y recorriendo durante la madrugada, portada a hombros, los 14 kilómetros que separan el santuario del núcleo urbano. Un recorrido marcado por lo arenoso y polvoriento del camino y la dureza de las condiciones que la imagen recorre cubierta completamente hasta que a la amanecida llega al pueblo. Llama la atención que, a pesar de las características de esta celebración y de la dureza física de la misma, el número de asistentes que acompaña a la talla

13. La movilización provocada por la devoción a la Virgen del Rocío arroja unos datos comparables a las principales movilizaciones marianas de la cristiandad, a pesar de que su estudio ha pasado con frecuencia desapercibido en los grandes autores y recibido atención principalmente de los autores locales. Así, puede compararse a la situación del paradigmático santuario de Lourdes, cuyo "número total de peregrinos ha ido descendiendo paulatinamente desde el año 1999 hasta situarse en la actualidad en torno a los 65.000 peregrinos". Unos datos que en España podrían medirse con las 160.000 comuniones anuales distribuidas en el santuario de la Virgen de la Cabeza de Andújar o las algo más de cien mil personas que desfilan en la ofrenda a la valenciana Virgen de los Desamparados. J. Aznar Sala (2019), 89 y ss.

14. E. Díaz Pérez (2011), 11, ha definido la romería como un "paganismo travestido de religiosidad".

15. [Redacción del diario] (8-IX-2019), Diario de Huelva. 
en el trayecto también ha ido creciendo exponencialmente ${ }^{16}$. En 2019 el Ayuntamiento de Almonte ha cifrado, a partir de la basura recogida, en un millón cuatrocientas mil personas los asistentes al traslado, en un dispositivo que exigió la coordinación de diversas administraciones públicas y el corte al tráfico rodado de algunas carreteras ${ }^{17}$.

\section{UNA PROBLEMÁTICA CONCEPTUALIZACIÓN}

La comparativa entre las dos devociones que hemos presentado a lo largo de los cien años que nos separan de 1919 nos permite hacer una aproximación historiográfica a la dimensión cultural de lo religioso a lo largo de este siglo. Hace pocos años, como resultado de un importante encuentro de investigadores de historia religiosa de la contemporaneidad habido en Alcalá de Henares, se expuso la necesidad de superar "la centralidad otorgada a las cuestiones políticas, lo que termina por desdeñar aspectos tan centrales e importantes como los socioculturales, especialmente los relacionados con la espiritualidad y la cultura devocional del momento" 18 . El estudio de las dimensiones culturales de lo religioso, en este caso a través de las devociones al Sagrado Corazón de Jesús y a la Virgen María en su advocación del Rocío, difícilmente puede sustraerse del debate sobre el proceso de secularización de la contemporaneidad habido en las últimas décadas.

La definición del concepto de secularización es problemática debido, en gran medida, a que lo "inabarcable e interminable" de las querellas académicas sobre el concepto han terminado por cargar el término de múltiples significados; de forma que "la secularización como concepto explicativo resulta inoperante para el estudio de la religiosidad en perspectiva histórica"19. A pesar de ello, no podemos sustraernos del éxito que el término ha tenido, especialmente a la hora de presentar la relación entre la religión y la modernidad desde la óptica de un proceso teleológico orientado a la cada vez menor relevancia de lo religioso. De hecho, la concepción de una

16. S. Padilla Díaz de la Serna (2007), 499 habla de "masificación" de los traslados desde 1977, año en el que la prensa cifró en 50.000 los peregrinos que acompañaron la imagen durante el trayecto y en 300.000 las personas que esperaban su llegada en Almonte.

17. URL: http://www.planvenida.es/ayuntamiento-y-hermandad-matriz-reanudan-su-trabajoen-la-comision-mixta-para-la-venida-2/ (consulta: 22-1-2020).

18. J. Louzao (2017), 285.

19. J. Louzao (2008), 333-334.

(C) Baetica. Estudios Historia Moderna y Contemporánea, 39, 2019, 369-395. Facultad de Filosofia y Letras, Universidad de Málaga. Departamento de Historia Moderna y Contemporánea 
tendencia progresivamente secularizadora de la modernidad ha llegado a asumirse de un modo tan general, que

se ha convertido en el prisma a través del cual observa el presente y el futuro de la religión no sólo una minoría de académicos, intelectuales o militantes laicistas, sino también el conjunto de la opinión pública occidental. Más aún, desde la categoría de 'secularización', han diseñado sus políticas religiosas -o la ausencia de las mismas- buena parte de los gobiernos occidentales y sus estrategias pastorales, asimismo, buena parte de las confesiones religiosas ${ }^{20}$.

Consciente del peligro de que en el ámbito de la sociología la vinculación entre la modernidad y la secularización se convirtiera en una "generalización ahistórica", Pérez-Agote ha planteado una explicación de la evolución de la religiosidad en España a partir de tres "oleadas secularizadoras". La primera tendría que ver con la separación entre la Iglesia y el Estado y se daría "a finales del siglo XIX y principios del XX"; la segunda estaría caracterizada por una secularización individual que habría tenido lugar a partir de los años sesenta como consecuencia del desarrollismo económico y de los efectos del Concilio Vaticano II y una tercera oleada sería la propia de quienes han sido socializados en culturas secularizadas a partir de los procesos anteriores ${ }^{21}$.

El autor ha explicado que los efectos de estas tres oleadas que plantea se superponen. Así puede interpretarse que el ambiente social en la España de hoy se aleja mucho del catolicismo cultural que caracterizaba el de nuestros bisabuelos y el itinerario vital de la mayoría de los ciudadanos cada vez es más independiente de los ritos tradicionales del catolicismo. Así, descienden el número de bautizados y de quienes completan la iniciación cristiana y mucho más lo hacen las ordenaciones sacerdotales y las profesiones religiosas. Mención especial merecen la situación de los matrimonios y las diferentes modalidades de familia que caracterizan la actualidad. En 2009 el número de matrimonios civiles en España superó por primera vez a los religiosos, y es cada vez más frecuente la vida de pareja sin casarse $\mathrm{e}^{22}$.

A pesar de ello, lo religioso no ha dejado de estar presente en la vida de las personas. Incluso, en muchos casos, quienes viven en una situación

21. A. Pérez-Agote (2012), 2-3, 7.

22. A. Pérez-Agote (2012), 142-145. 
heterodoxa desde el punto de vista moral participan de multitud de actos de piedad y confiesan mantener una relación más o menos frecuente con lo sobrenatural a través de sus creencias. Por ello, parece conveniente distinguir entre las "creencias y prácticas"; entre "el culto, las devociones populares, la moral personal y social" 23 .

Todo ello nos devuelve a las limitaciones del concepto de secularización, tan debatido en las últimas décadas. Peter Berger, defensor de la teoría de la secularización algunos años antes, afirmó al filo del cambio de siglo acerca del propio concepto: "Modernization necessarily leads to a decline of religion, both in society and in the minds of individuals. And it is precisely this key idea that has turned out to be wrong"24. Por su parte, Pérez-Agote, aun sin renunciar a la utilidad del término, concluye que

debemos pertrecharnos de instrumental analítico para acercarnos a las variadas situaciones en las que la religión se encuentra a lo ancho del mundo y a lo largo del tiempo. Desde la perspectiva del cambio religioso, la noción de secularización debe desembocar en marcos analíticos evitando así la idea de universalidad y de transhistoricidad, y la pretensión teleológica ${ }^{25}$.

Se ha insistido, por tanto, en la necesidad de "historizar" como ocasión para "considerar la singularidad de los casos" 26 . La comparativa de los cien años que han pasado entre la consagración de España al Sagrado Corazón y la coronación canónica de la Virgen del Rocío y la realidad que representan ambas devociones al conmemorarse el centenario de estas efemérides nos ofrece un espacio a la reflexión por cuanto la piedad católica parece haberse modificado, pero no necesariamente mermado, en una sociedad que ha experimentado "oleadas secularizadoras". De hecho, algunos de los procesos de desarrollo de estas devociones coinciden con los momentos que se han señalado para el declive de lo religioso, como es el caso del Rocío que tiene el siglo XX como "el gran siglo de su historia" coincidiendo lo más intenso de su expansión devocional a partir de los años sesenta con las pretendidas olas de secularización individual ${ }^{27}$.

En cualquier caso, al tratar de devociones nos movemos especialmente en un ámbito de marcado componente popular dentro de lo religioso, es

23. L. S. Cunningham (2014), 6.

24. P. L. Berger (1999), 3.

25. A. Pérez-Agote (2012), 19.

26. J. DE la Cueva (2015), 386.

27. S. Padilla díaz de la Serna (2007), 16.

(C) Baetica. Estudios Historia Moderna y Contemporánea, 39, 2019, 369-395. Facultad de Filosofia y Letras, Universidad de Málaga. Departamento de Historia Moderna y Contemporánea 
decir, con "prácticas religiosas distintas, más que contrarias, a la religión oficial e institucionalizada, y estrechamente ligadas a la cotidianeidad de las personas". Unas prácticas que a lo largo de la contemporaneidad se han venido recuperando y afianzando ${ }^{28}$.

Padilla Espina relata una anécdota habida en Almonte hacia los años cincuenta del siglo XX que bien puede ejemplificar la relación entre la religiosidad oficial y la piedad popular a que hemos aludido:

... Habían llegado sus últimos momentos en esta vida, y D. Carlos, que se señaló en Almonte, por la magnífica labor de apostolado que hizo entre los más desheredados y los enfermos del pueblo, lo visitaba a diario, con el ánimo de administrarle el Santo Sacramento de la Extrema Unción de Enfermos. Sr. Juan, el protagonista de esta historia, y sólo Dios sabe de cuántas otras, moribundo, en pleno uso de sus facultades mentales, en la cuenta atrás de sus últimos días en esta vida se resistía una y otra vez a recibir el referido Sacramento. Hombre de escasa ilustración, no había sido cristiano practicante en su vida, y no sabía por tanto, cuál era el significado y el valor del Sacramento. Una y otra vez, cada vez con menos fuerzas, le manifestaba a D. Carlos: 'Pero D. Carlos, si yo no he hecho nunca mal a nadie, yo lo único que he hecho en mi vida ha sido trabajar y trabajar de sol a sol para sacar mi familia adelante. Yo no necesito confesarme'. D. Carlos, sin embargo, persistía en su misión, en sus deseos de confortar al anciano espiritualmente con todas las cualidades del Sacramento.- Un día, alguien hablando del tema con el sacerdote le apuntó: 'D. Carlos, y no se le ha ocurrido a usted hablarle al Sr. Juan de la Virgen del Rocío'. ‘Caramba!' -dijo D. Carlos-, que entonces estaba recién llegado, 'pues no se me ha ocurrido'. Un fallo de principiante. Al día siguiente, cuando fue a visitar al anciano, éste ya en un estado crítico de salud, lo primero que le preguntó cogiéndole de la mano fue: '¿Sr. Juan, cuántas veces se ha metido usted en su vida debajo del paso de la Virgen del Rocío?'. Fue como provocar el trance de mejora del anciano, antes de su muerte. A Sr. Juan, que permanecía con los ojos cerrados, se le abrieron e iluminaron los ojos como platos, y apretando la mano del joven sacerdote, con la mirada perdida, le contestó: 'Yo, muchas veces, D. Carlos, muchas veces me he partío [sic] el pecho debajo de las andas de la Virgen'. 'Y usted Sr. Juan -le preguntó intencionadamente D. Carlos- ¿qué sería capaz de hacer ahora mismo por la Virgen del Rocío?'. 'Por la Virgen del Rocío. Yo, D. Carlos, yo' -el anciano sacó fuerzas de donde no tenía-, e incorporándose de la cama le contestó. 'Yo soy capaz ahora mismo de toreá, de toreá [sic] si hace falta por mi Virgen del Rocío'. Ante esta imponderable y emocionante

28. J. LouZao (2008), 342.

C Baetica. Estudios Historia Moderna y Contemporánea, 39, 2019, 369-395.

Facultad de Filosofía y Letras, Universidad de Málaga. Departamento de Historia Moderna y Contemporánea 
actitud y respuesta del anciano moribundo, D. Carlos le manifestó: 'Pues Sr. Juan, la Virgen del Rocío, lo único que te pide en estos momentos, es que te confieses'. Y Sr. Juan se confesó ${ }^{29}$.

Por su parte, Pérez-Agote ha caracterizado las "formas de construcción del sentido de la vida en la sociedad española contemporánea" en busca de una comprensión de las distintas actitudes de los españoles de hoy hacia lo religioso. Una de las dimensiones que ha tenido en cuenta ha sido su relación con la piedad popular. Es llamativo que, de los ocho grupos que tipifica, tan sólo tres de ellos tengan una actitud próxima respecto a las formas de piedad popular: el "catolicismo tradicional" (estudiado a partir de un grupo de mujeres de un pueblo andaluz de en torno a 55 años que presenta como casadas y con varios hijos, de práctica religiosa semanal, con estudios primarios y votantes del PP); el "catolicismo vacío", presentado sin embargo sin implicación personal en el fenómeno (estudiado a partir de un grupo de hombres y mujeres de entre 45 y 54 años, casados religiosa o civilmente, con estudios primarios o de formación profesional e ideología de centro-izquierda); y el "catolicismo desengañado" (estudiado en un grupo de hombres y mujeres de entre 35 y 45 años, casados, con formación superior y cierta neutralidad tanto política como religiosa) ${ }^{30}$.

A partir de este análisis parecería harto improbable que un fenómeno como la devoción popular al Sagrado Corazón o a la Virgen del Rocío hubiese aumentado, puesto que los espacios sociales para que puedan sumarse vínculos personales a las formas de piedad que referimos han ido progresivamente reduciéndose. Sin embargo, al mirar la evolución experimentada por las devociones que comparamos a lo largo del siglo que acaba de terminar, esta conclusión debe matizarse.

El enorme crecimiento experimentado por la devoción a la Virgen del Rocío contrasta con la resignificación que ha sufrido en estos cien años la devoción al Sagrado Corazón de Jesús. Después de la consagración de España en la inauguración del monumento situado en el centro geográfico de la Península, Alfonso XIII quedó religiosamente identificado con la causa del reinado social del Corazón Divino. Después del gesto, el rey recibió tanto felicitaciones particulares como "anónimos que le amenazaban de muerte". En 1923, el papa Pío IX confiaba en "todo lo que debemos y podemos esperar de él cuando se trate de defender a aquella Religión santa,

29. S. Padilla Díaz de la Serna (2007), 63.

30. A. Pérez-Agote (2012), 167-311. 
a la cual debe España toda su grandeza". La vinculación entre el monarca y la consagración habría, por tanto, de producir una importante quiebra en la devolución a partir del advenimiento de la Segunda República. Tan es así, que la fiesta instituida para conmemorar el aniversario de la consagración hubo de dejar de celebrarse y la devoción quedó muy vinculada a posiciones políticas conservadoras o reaccionarias ${ }^{31}$.

En la actualidad, la devoción al Sagrado Corazón presenta una penetración popular más limitada que en otras épocas. Vinculada a fieles católicos con una fuerte identificación con la Iglesia, para pervivir se ha optado por potenciar otros aspectos de su significación teológica insistiendo sobre la misericordia divina y alejándose de las coordenadas de identificación nacional, monarquía, tradición española y otros significados asociados al nacionalcatolicismo que saturaron esta devoción de contenido político, como ya apuntamos. Por el contrario, la devoción hacia el icono mariano que fue coronado pocos días después de la consagración leída por Alfonso XIII no ha dejado de crecer desde entonces, hasta el punto de convertir el santuario de la marisma de Huelva en uno de los principales centros de devoción mariana de toda la cristiandad. Si atendemos al número de hermandades filiales de la Virgen del Rocío fundadas en este siglo, los datos resultan muy llamativos en relación con el proceso secularizador de la España de los siglos XX y XXI. De las 113 hermandades filiales de la patrona de Almonte establecidas desde 1919 a la actualidad, 3 lo fueron en los doce años siguientes a la coronación ${ }^{32}, 9$ durante los cinco años de la Segunda República, 23 durante el franquismo -15 de ellas a partir de los años sesenta, en que la sociedad comienza a asimilarse a los parámetros sociales europeos (en 1962 se funda la Hermandad de Madrid)- y las 77 restantes desde el establecimiento de la democracia a la actualidad. De esta forma, pareciera que en los periodos de mayor libertad política y en que la vivencia de lo religioso se distancia de las estructuras del Estado, el crecimiento de la devoción a la Virgen no sólo no disminuye, sino que aumenta con mayor insistencia ${ }^{33}$.

Esta casuística no puede encajarse fácilmente en las explicaciones sociológicas sobre la secularización. Corre el riesgo, por tanto, de ser presentada como "una rémora del pasado y del arcaísmo, más que como un

31. L. CANo (2009), 90, 149, 164.

32. En este periodo constan 4 hermandades filiales: Carrión de los Céspedes, Benacazón, Trigueros y Gines, pero Benacazón fue fundada en 1915.

33. Datos de la Hermandad matriz de Almonte: URL: https://hermandadmatrizrocio.org/ hermandades-filiales/ (consulta: 17-10-2019). 
problema teórico" por el hecho de contravenir el aspecto teleológico del paradigma secularizador. Sin embargo, la expansión devocional del Rocío no hubiera podido darse sin unas condiciones de modernización que no eran posibles en el pasado, como tendremos ocasión de presentar en el siguiente apartado. Cabe, por tanto, remarcar que el fenómeno religioso es más que una conducta habitual (ir a la iglesia) o una actividad cognitiva que cuente con creencias lógicas, abarcando también otros aspectos de la vida, más difícilmente objetivables mediante encuestas o entrevistas ${ }^{34}$.

El sociólogo Javier Aznar ha propuesto el término religamiento para referirse a la experiencia propia de aquellos que descubren lo religioso -especialmente jóvenes- después de haber vivido durante algún tiempo en un ambiente y con un horizonte vital alejado de cualquier significación trascendente. Ha llamado la atención sobre la incidencia de la devoción mariana en el fenómeno, a pesar de que la creencia en la Virgen no sale bien parada en las encuestas de Pérez-Agote ${ }^{35}$. Aznar afirma que:

La constatación empírica del religamiento, que se da al tiempo con la secularización, tiene una de sus máximas expresiones en la devoción mariana. Nunca antes los santuarios marianos han sido tan visitados como ahora ni la figura de la Virgen ha experimentado tanta atracción y devoción por parte de los fieles ${ }^{36}$.

Aun aceptando la propuesta del religamiento como fenómeno inverso y simultáneo a la secularización que encuentra en las formas de piedad un elemento clave en su expresión, entendemos que la realidad a la que se refiere no es exclusiva del momento presente, sino que puede también rastrearse -con matices- en el pasado. También en otros periodos existieron multitud de fenómenos de religiosidad popular en los que se movilizaron no sólo fieles católicos plenamente identificados con la doctrina y la moral de la Iglesia, sino otros muchos que sin tener una identificación tan plena o participando acaso tan sólo de un sentimiento genéricamente religioso acudieron a las convocatorias propias de la religiosidad popular, como tuvimos ocasión de presentar mediante la anécdota del Sr. Juan. Por ello, consideramos adecuado referirnos a este tipo de movilizaciones como espacios de "frontera de la Iglesia", dado que

34. J. LouZao (2008), 337, 341.

35. A. Pérez-Agote (2012), 120-122.

36. J. Aznar Sala (2019), 89. 
en su participación conviven quienes poseen una fuerte creencia y un sólido sentido de pertenencia a la comunidad de los fieles con aquellos que no cuentan con vínculos tan profundos, pero que de una u otra manera se sienten identificados con esta fe religiosa o con algunos de los elementos de su expresión popular ${ }^{37}$.

Lo que sí parece constatable, a partir de la comparativa entre la devoción al Sagrado Corazón y la Virgen del Rocío a lo largo del último siglo, es que el espacio donde ha crecido cuantitativamente la capacidad movilizadora de lo religioso ha sido en estos espacios de "frontera de la Iglesia". Si la separación de lo religioso y lo cívico ha sido uno de los principales rasgos que diferencian a España entre 1919 y la actualidad, este cambio ha afectado negativamente a devociones como el Sagrado Corazón de Jesús que en su día fueron saturadas de vínculos ideológicos y, sin embargo, ha favorecido el crecimiento de devociones como la rociera, que alcanza cifras vertiginosas de movilización en nuestros días. Una devoción de la que Murphy y González Faraco han destacado insistentemente que ha permanecido bajo el control del pueblo de Almonte mediante su Ayuntamiento y la Hermandad Matriz, limitando la injerencia de las instituciones eclesiásticas superiores y de las autoridades civiles foráneas ${ }^{38}$.

A modo de hipótesis de trabajo, Julio de la Cueva recogió de HerviuLéger las imágenes del "converso" y del "peregrino" como paradigmas de la pervivencia de lo religioso después de las décadas de una secularización generalmente aceptada, presentando una "modernidad racionalista y humanista, que alimentaba en el individuo la utopía de la autorrealización ilimitada y que, de esta manera, lo empujaba paradójicamente a situarse en un plano eminentemente religioso". Sin exclusión de la otra, la del peregrino es, sin duda, la que más se adapta al fenómeno de movilización popular que parece vivir un momento dorado en el catolicismo español de nuestros días, cuanto menos en lo que a piedad popular se refiere. Este icono permite insistir en la importancia de la dimensión individual de lo religioso y en la capacidad de seleccionar de la religión los elementos que más adecuados resultan en cada momento, sin sentirse interpelado por rechazar el resto en una suerte de "bricolaje religioso" 39 .

El espacio de "frontera de la Iglesia" en el que puede darse este tipo de vinculación con lo religioso tiene como característica fundamental, al

37. S. Navarro de la Fuente (2014), 111.

38. M. D. Murphy y C. González Faraco (2002); (2013).

39. J. DE la Cueva (2015), 383-384. 
igual que el religamiento, una carencia importante de formación doctrinal básica sobre los principios del cristianismo. Por ello, los espacios de vivencia de lo religioso mediante manifestaciones populares son acaso más frecuentados hoy día por quienes aspiran a un vínculo con lo trascendente, pero sin mantener -al menos inicialmente- un compromiso institucional con la Iglesia. Una particularidad que se añade a los casos en los que, con independencia de la formación que se tenga sobre doctrina católica, los fieles son conscientes de vivir en una situación claramente opuesta a las enseñanzas morales del catolicismo y no por ello se privan de identificarse con lo sagrado a través de estas expresiones. Un ejemplo de ello puede seguirse en algunas conductas sexuales fuera de la moral católica que se viven durante la romería de Pentecostés y cuyos protagonistas reconocen una profunda devoción por la Virgen del Rocío, sin que se muestren dispuestos a renunciar ni a sus prácticas ni a su piedad religiosa ${ }^{40}$.

En cualquier caso, lo llamativo del crecimiento de la devoción a la Virgen del Rocío durante el siglo que nos separa de su coronación canónica es que alcanza unos niveles que enfrentan la dimensión del fenómeno a la naturaleza misma de las cosas: la procesión de la Virgen ha aumentado muchísimo el tiempo de su duración para favorecer el encuentro entre todas las hermandades y la imagen sagrada y hoy día se debate la posibilidad real de sostener el esfuerzo físico que supone extender la procesión durante tan largo tiempo, los caminos por los que transitan los romeros han de ser preparados por un dispositivo especial que coordina a distintas administraciones públicas y se ha hecho imprescindible extender los tiempos de tránsito para poder albergar a las crecientes comitivas que los recorren... Este fenómeno expansivo, que no hubiera sido posible sin una modernización de la fiesta y de la devoción, parece encajar mejor en la propuesta de una "recomposición" religiosa de la modernidad planteada por Louzao ${ }^{41}$.

\section{LOS MECANISMOS PARA LA "RECOMPOSICIÓN RELIGIOSA" DE LA MODERNIDAD}

El propósito de "historizar" sobre estas dos devociones a partir de las efemérides que se cumplen debe llevarnos no sólo a comparar la situación de ambos objetos de atención a lo largo del último siglo, sino que también debe penetrar en los factores que motivan la evolución que hemos

40. E. DíAz-PÉrez (2001), 49-54.

41. J. Louzao (2008).

(C) Baetica. Estudios Historia Moderna y Contemporánea, 39, 2019, 369-395. Facultad de Filosofia y Letras, Universidad de Málaga. Departamento de Historia Moderna y Contemporánea 
presentado. En este caso, las causas que expliquen el cambio lo serán de las variaciones habidas en ambas devociones, pero -muy especialmentepodremos presentarlas como los mecanismos que han servido a lo religioso para perpetuarse e, incluso, llegar en una posición de cierta fortaleza a la postmodernidad.

A finales del pasado siglo, se constató que la crisis de adhesión a las religiones sólidamente instituidas no estaba reñida con el progreso de las "religiones" entendidas en un sentido amplio.

Nuestra época es evidentemente de disminución en la pertenencia a las religiones establecidas y, a la vez, de surgimiento, por doquier, de nuevas formas de experiencia religiosa, simplemente independientes las unas de la ortodoxia recibida, aunque sin romper con ella, totalmente alejadas otras de institucionalización, erráticas algunas; 'supersticiosas', como antes se decía, no pocas ${ }^{42}$.

La actualidad contiene numerosas muestras de comportamientos ambiguos entre lo religiosamente ortodoxo, lo que no y una multitud de situaciones intermedias. Es lo que ha podido designarse como "bricolaje" a la hora de construir el sentido de la vida y una comprensión del mundo no siempre coherente $^{43}$. Sin embargo, en los casos que seguimos y muy especialmente en el de la devoción a la Virgen del Rocío, a pesar de la evidente distancia entre la doctrina moral de la Iglesia y algunas prácticas de los fieles, no deja de estar presente una vinculación formal con la institución eclesiástica. No se trata, por tanto, de formas privadas de experiencia religiosa o desprovistas de la mediación de instituciones; sino más bien al contrario, de la pervivencia de un vínculo con lo espiritual a través de medios propios de instituciones eclesiales canónicamente establecidas y con las que las personas mantienen apego, a partir de las que se vinculan con la trascendencia, a pesar de no vivir siempre conforme a la moral establecida.

De esta forma, es preciso valorar los límites de la pretendida decadencia institucional, aun cuando sea sólo por la capacidad de las instituciones de generar una capa "de frontera" en la que el mantenimiento de los vínculos compensa la distancia en los modos de vida. Ciertamente, como han señalado Murphy y González-Faraco, en el caso del Rocío el poder de la Iglesia entendida como jerarquía en sentido tradicional es muy limitado ${ }^{44}$.

42. J. L. Aranguren (1996), 21.

43. A. Pérez-Agote (2012), 22.

44. M. D. Murphy y C. González Faraco (2013), 104. 
Sin embargo, conviene no perder de vista que la Hermandad Matriz no deja de ser una institución propiamente eclesiástica, aun cuando sea "una institución singular, difícilmente igualable en sus características, atribuciones, poderes y responsabilidades dentro de la Iglesia Católica" ${ }^{45}$. Una pertenencia a la Iglesia que comparten el resto de las hermandades rocieras.

Este espacio "de frontera" de la Iglesia ha de reconocerse en la enorme popularidad actual de determinadas formas de piedad católica con un importante peso de apertura a lo espiritual. En ellas no puede negarse un componente de trascendencia que, aún integrado en instituciones propiamente eclesiales, no muestra la identificación plena con la Iglesia. Desde luego, no en el modo en que lo evidenciaron gestos como la consagración al Corazón Divino en 1919. El resultado, es una fe religiosa mucho menos dogmática, que probablemente se resiste a asumir en lo personal todo un credo y -muy especialmente- un determinado código de conductas morales a él asociado; y que es vivida, fundamentalmente, de un modo personal y con unos vínculos institucionales relativamente laxos, aunque no inexistentes. Esta situación intermedia, entre la adhesión a la institución eclesial y el rechazo o no asunción de determinadas implicaciones de esta pertenencia debe verse -entendemos-, no sólo como un rasgo de la religiosidad contemporánea, sino también como un mecanismo de pervivencia de lo religioso en la actualidad, es decir, una clave para la "recomposición religiosa de la modernidad". Una situación que, comparativamente, es lógico que beneficiara mucho más a una devoción de origen popular que a otra que se mostraba fuertemente vinculada a un determinado contenido ideológico y político que otorgaba a la Iglesia como institución una sólida posición de dominio social.

Este componente popular de la devoción mariana no es exclusivo del caso del Rocío, sino que afecta en general al culto a la Virgen María en nuestros días. Así, se ha destacado que:

... Últimamente han proliferado en la sociedad, o al menos no han descendido pese a la creciente secularización, las medallas donde aparece el rostro de la Virgen y los escapularios que piden su protección y amparo. Todo ello habla de religamiento. Es incluso posible que se porten más imágenes o medallas marianas que cruces, cuando la cruz es el máximo símbolo de expresión cristiana. La razón de esto puede encontrarse en que para el mundo irreligioso la cruz representa una adhesión muy marcada de la práctica y religión cristiana

45. S. Padilla Díaz de la Serna (2007), 15.

(C) Baetica. Estudios Historia Moderna y Contemporánea, 39, 2019, 369-395. Facultad de Filosofia y Letras, Universidad de Málaga. Departamento de Historia Moderna y Contemporánea 
que pide mayor testimonio de vida y valentía en su compromiso, mientras que la medalla de la Virgen toca el aspecto más humano de hijo en referencia a una madre, cuya expresión se presenta con mayor fortaleza y universalidad, más alejada de lo institucional ${ }^{46}$.

En reafirmación de lo anterior, la experiencia sugiere que existen diferencias incluso en el uso de medallas o símbolos de determinadas devociones, de forma que a más popularidad de la devoción menor grado de exigencia se impone y más se acepta socialmente su uso. La difusión universal de la silueta de la Virgen del Rocío es un caso paradigmático en este sentido, habiéndose llegado incluso a la configuración de medallas, objetos diversos e incluso tatuajes que, combinando su forma, pero prescindiendo de su representación completa, consiguen recordar a la Virgen sin representarla propiamente. De esta forma, tan sólo los que detectan que la silueta remite al icono mariano se percatan de que en realidad se trata de un símbolo religioso.

Otros cambios principales de los últimos años han incidido mucho sobre el fenómeno de la religiosidad popular. Cronológicamente, quizás el primero de ellos tuvo que ver con la reivindicación de las formas de piedad tradicionales como elementos culturales propios y como valores de identidad a conservar y potenciar. La defensa del folclore popular pudo convertirse así en un mecanismo para trasladar lo religioso a nuevos tiempos. En el caso andaluz, el fenómeno ha contado con dos características particulares que han podido favorecer el crecimiento del fenómeno devocional rociero. En primer lugar, la búsqueda de referentes útiles de identidad colectiva de la población y posteriormente la consolidación autonómica de Andalucía encontraron en el Rocío una fiesta de enorme riqueza. Vinculada al medio natural de la región y también integrada en buena parte por su medio urbano rural, la fiesta combina un fuerte componente popular, con una riqueza musical propia, en un entorno natural exclusivo y con capacidad de vincular a través de "los caminos" multitud de espacios dispares de la región. Quizás ello justifica la amplia cobertura que los medios han dedicado a la fiesta ${ }^{47}$.

Con todo, este rasgo no sería causa de expansión hasta el punto de vincularse con el aumento exponencial de participantes y "aficionados" a la celebración, sin contar con el moderno desarrollo de las comunicaciones

46. J. Aznar Sala (2019), 104.

47. S. Padilla Díaz de la Serna (2007), 231, 512-532. 
entre ciudades que permite asistir con mayor facilidad que en el pasado al santuario. Y ello, dado que la mejora de carreteras y medios de transporte no sólo favorece la participación en la romería, sino también la visita asidua de los devotos al santuario de la Virgen, convertido desde hace décadas en un verdadero centro de peregrinación mariana. Santiago Padilla, al tratar sobre la expansión de la devoción rociera entre los años cuarenta y ochenta del siglo XX, ha destacado la trascendencia de la creación de la carretera desde Almonte hasta El Rocío, que no fue una realidad hasta 1959. Se iniciaron entonces una serie de transformaciones que permitieron la modernización de la devoción. En 1969 fue bendecido el nuevo y actual santuario después del derribo de la anterior ermita y se puso así fin a una década que había visto importantes mejoras, como la electrificación de la aldea de El Rocío en $1964^{48}$. Hasta entonces no contó El Rocío con infraestructuras parecidas a las que en 1919 había estrenado el monumento al Sagrado Corazón en el Cerro de los Ángeles, para cuya construcción sobró dinero del medio millón de pesetas recaudado, destinándose lo sobrante al obispo de Madrid-Alcalá para que construyese una cripta o convento de religiosos que custodiasen el monumento y atendiesen el culto de la ermita de la Virgen de los Ángeles ${ }^{49}$.

Para superar distancias, es necesario, en cualquier caso, la asunción de determinados gastos. Si, además, el modo de superarlas es el propio de una romería de varios días de duración, es preciso contar con la capacidad adquisitiva de los asistentes para poder asumir los costes de la peregrinación. En este sentido, no podría explicarse el auge devocional -o, al menos, su expresión- sin el aumento de poder económico de los españoles experimentado desde la segunda mitad del siglo XX. Se trata, además, de un fenómeno que afecta tanto a los fieles que individualmente participan como a las instituciones que velan por esta participación. De esta forma, las diferentes hermandades rocieras -como también el resto de asociaciones de fieles que podríamos incluir en ese tejido de "frontera de la Iglesia"- también deben asumir importantes gastos que exigen una estructura económica relativamente sólida. Todo ello, referido en principio sólo a la extensión de la devoción y a su expresión, pero teniendo también presente que en la mayoría de los casos la búsqueda de recursos se orienta a la promoción de determinadas iniciativas de carácter social. De hecho, con ocasión del centenario de la coronación canónica de la Virgen del Rocío,

48. S. Padilla Díaz De La Serna (2007), 174, 342, 267.

49. L. CANO (2007), 86

(C) Baetica. Estudios Historia Moderna y Contemporánea, 39, 2019, 369-395. Facultad de Filosofia y Letras, Universidad de Málaga. Departamento de Historia Moderna y Contemporánea 
muchas de las Hermandades se han propuesto como obra social participar en la construcción de una planta oncológica para pacientes adolescentes (distinta de los enfermos pediátricos y de los adultos) en el centro hospitalario sevillano que lleva el nombre de la Virgen. Iniciativa sugerida por la asociación de padres de niños con cáncer ANDEX ${ }^{50}$.

Otro de los factores que ha podido favorecer la extensión de la devoción está en el desarrollo digital. En primer término, abriendo una serie de posibilidades desconocidas antes. Sirva de ejemplo el que la Hermandad Matriz de Almonte haya puesto mucho cuidado en la difusión en directo a través de sus perfiles en redes sociales de cuestiones relativas a la devoción a la Virgen. De esta forma, tanto las noticias de interés como los actos de culto pueden ser seguidos mundialmente en tiempo real. Una situación que no sólo afecta a la romería o actos de especial relevancia, sino también a actos de culto tan cotidianos como las misas de los sábados o la salve que a diario se reza ante la imagen en Almonte durante el tiempo que permanece en el núcleo urbano. La comparativa entre ambas devociones en este campo no deja de ser ilustrativa: la cuenta oficial de Instagram del Santuario del Sagrado Corazón en el Cerro de los Ángeles cuenta con 289 seguidores, la de la Hermandad Matriz de Almonte $10.800^{51}$.

En este sentido, nos atrevemos a apuntar una tendencia que podría abrir cauce a nuevas interpretaciones. El uso de las nuevas redes sociales para la promoción de actividades religiosas ha creado una suerte de "especialización sectorial" entre los amantes de estas formas de piedad. Así, mientras que décadas atrás los más adeptos a estas manifestaciones podían ser considerados individuos relativamente particulares en sus ambientes habituales, la puesta en contacto virtual con otras personas que comparten sus aficiones ha generado una cierta impronta de "comunidad" que se moviliza e interrelaciona a través de los nuevos medios y que traslada a cada celebración en concreto a una importante cantidad de individuos que, en muchos casos, coinciden en multitud de convocatorias de corte similar. Quizás esta perspectiva pueda ser abordada en lo venidero con más profundidad.

50. URL: https://hermandadmatrizrocio.org/la-hermandad-matriz-pone-en-valor-el-compromiso-de-las-hermandades-con-la-obra-social-del-centenario/ (consulta: 24-1-2020). URL: http://andexcancer.es/planta-zero/ (consulta: 24-1-2020).

51. Consultas en el perfil de Instagram de ambas instituciones (hdadmatrizalmonte y scerrodelosangeles) 24-1-2020. 


\section{A MODO DE CONCLUSIÓN}

A la vuelta de los cien años que nos separan de la consagración de España al Sagrado Corazón, su fiesta ha estado marcada por una celebración de perfil bajo en la que la Iglesia ha querido resignificar el acto que conmemoraba potenciando la veneración de la misericordia divina y atenuando la ordenación de la vida social española a los preceptos del catolicismo. Bien es cierto que, en origen, el significado teológico de la devoción al Sagrado Corazón estaba orientado en este sentido; pero no lo es menos que la mayor influencia de esta devoción en la España contemporánea fue bajo el signo de un fuerte componente ideológico de reconquista católica de la sociedad moderna. Es preciso también matizar que, teológicamente, la fiesta del Sagrado Corazón continúa siendo una de las más significativas de cuantas en el catolicismo están relacionadas con Jesucristo, siendo de las pocas festividades que conservan el rasgo de solemnidad litúrgica sin celebrarse en domingo. Sin embargo, esta alta consideración eclesial no hace sino poner de relieve su limitada incidencia social en la actualidad. En contraste, la devoción a la Virgen del Rocío, a los cien años de su coronación canónica, concentra a movilizaciones humanas verdaderamente sorprendentes, que suponen en cada edición un nuevo reto a las autoridades organizadoras dado que, en la secularizada España de "después del cristianismo", el número de los que asisten a las procesiones supera en muchos casos la capacidad de las calles y las proporciones lógicas de las comitivas.

Esta constatación nos hace profundizar, no sólo en las limitaciones del concepto de secularización, sino también en la capacidad de las religiones institucionalmente constituidas en general, y el catolicismo en concreto, para continuar generando fenómenos de masas. No parece que la veneración de una imagen del siglo XIII que alcanza las más altas cotas de expansión de su culto en la actualidad (y esto, en mayor o menor medida podría decirse de otros casos menos llamativos) sea síntoma de una pérdida irreversible de influencia del catolicismo en la sociedad contemporánea. Lo que sí es constatable, y la comparativa entre las devociones analizadas así lo deja ver, es que lo católico ha perdido la íntima vinculación con el poder civil, la posición de predominio social y su imbricación con el discurso de identidad nacional que fue objeto de su movilización durante las centurias precedentes. Este fenómeno es. probablemente, el que mejor puede designarse con el término de secularización.

Esta pérdida de la íntima vinculación del Estado con lo católico ha resultado, sin embargo, enormemente trascendente para la vivencia cotidiana del catolicismo a lo largo de las diez décadas que nos separan de 1919. La 
religiosidad ambiental del país, el respeto social por las personas y cosas sagradas y, especialmente, el conocimiento de los rudimentos doctrinales básicos del catolicismo parecen haberse perdido en amplísimas capas de la población. Como resultado, la religión católica es generalmente percibida como parte del sustrato cultural de la actualidad, pero profundamente desconocida por cada vez más capas de la población en su doctrina y prácticas. Este desconocimiento de origen posibilita, en el caso de la permanencia de lo religioso, tanto las figuras del "converso" como del "peregrino" como imágenes propias de la adaptación de lo religioso a la vida cotidiana de nuestros días, situándose esta última en ese espacio social de "frontera de la Iglesia" que se moviliza especialmente mediante la religiosidad popular.

La tendencia de los últimos años nos demuestra que la movilización religiosa en estos ambientes no sólo no ha decrecido, sino que incluso ha ido progresivamente creciendo. El caso de la devoción a la Virgen del Rocío, patrona de Almonte, es paradigmático en este sentido. Su estudio revela, además, que el crecimiento de la devoción (al menos de las instituciones encargadas de su promoción) se ha desarrollado con mucha más intensidad en periodos de libertad ideológica y de secularización creciente antes que en momentos de especial imbricación entre la Iglesia y el Estado. Y ello hasta el punto de situar la devoción en el punto de mayor extensión de su historia, y la masiva participación de fieles en las distintas convocatorias en el límite de lo organizativamente posible.

A partir de este análisis, sin perder de vista nuestra pretensión de "historizar" sobre casos concretos que nos permitan ver la capacidad de los conceptos propios de la sociología religiosa para progresar en el ámbito de una historia cultural de la religión, podemos apreciar las enormes consecuencias estructurales del proceso secularizador. Incluso, podemos concretar algunas de las implicaciones de la secularización de la sociedad en la praxis vital de muchas personas que, incluso a la hora de pretender una incorporación a la Iglesia o algunas de sus prácticas, se enfrentan a la falta de conocimiento de los principios fundamentales del catolicismo. Sin embargo, no podemos asumir igualmente que lo religioso en general y lo católico en concreto hayan dejado de contar con una enorme incidencia en la vida de las personas. También en el plano institucional, aun cuando el sentido de pertenencia se deba antes al mantenimiento del rito que la adhesión al ideal ético. El crecimiento de la devoción a la Virgen y el incremento de participantes y asistentes a muchos ritos tradicionales del catolicismo así lo ponen de manifiesto.

Existen diversos factores que nos permiten explicar el modo en que lo religioso ha conseguido mantener su influencia en la vida de las personas 
con independencia de la creciente secularización. En el fondo, estos factores pueden aproximarnos a explicar cómo se ha producido este tránsito entre la movilización religiosa en una sociedad tradicionalmente católica a la propia de una sociedad secularizada. Que ello se deba a una sed de trascendencia en el ser humano contemporáneo que busca nuevas vías de expresión - o la renovación de las tradicionales- o a la capacidad de la Iglesia para buscar nuevos espacios en las sociedades contemporáneas es, en gran medida, una incógnita por resolver. Pero en cualquier caso, su respuesta se haya vinculada al proceso de "recomposición religiosa" de la modernidad.

El hecho de que no pueda admitirse duda de la pérdida de influencia ambiental de lo religioso, como tampoco de la incidencia de la religión en la vida de muchas personas podría llevarnos a considerar si el concepto de laicidad, aun trasladado a lo social antes que a lo político, podría ser más adecuado que el de secularización. En realidad, la propuesta no es baladí por cuanto la cuestión abre otro debate más profundo y de más largo recorrido. Y es que, considerando la historia no sólo como el espacio de los cambios sino también de las permanencias, cabría preguntarse si en la vida cotidiana de otros periodos históricos existió una praxis religiosa "no secularizada" o si, por el contrario, aun en una sociedad formalmente católica la vivencia práctica de la fe religiosa por parte de los individuos concretos no fue tan diferente de la que es propia de la actualidad. En este sentido, como hemos apuntado, el origen de la devoción al Sagrado Corazón en el siglo XVII ya estaba vinculado a la reparación piadosa para con Jesucristo a partir de las ofensas que recibía por los descreídos o tibios en la sociedad del Antiguo Régimen.

En definitiva, nos referimos al cuestionamiento sobre si, en las sociedades en que esta laicidad del poder no existía y la Iglesia continuaba siendo una institución social de primera magnitud, había una mayor religiosidad cultural en los fieles o no. Existen indicadores que podrían iluminarnos algunas respuestas en este sentido, como las estadísticas de cumplimientos pascuales, los informes sobre prácticas sacramentales o los propios de las visitas ad limina pueden ser muy reveladores. Quizás ello muestre que la práctica cultural católica de los fieles españoles en la contemporaneidad no estuvo demasiado alejada de los parámetros actuales y que, por tanto, la secularización ha sido más profunda a nivel político, social e institucional que en la vida cotidiana de las personas. De ser así, la idea de secularización serviría como criterio estructural, pero perdería buena parte de su utilidad en el campo concreto de una historia cultural de lo religioso, centrada en las prácticas de los fieles corrientes. Un campo en el que, a partir de lo que hemos podido vislumbrar, queda todavía mucho por escribir. 


\section{BIBLIOGRAFÍA}

[Redacción del diario], "La procesión extraordinaria de la Virgen del Rocío congrega a más de 500.000 personas", Diario de Huelva, 8 de septiembre de 2019. URL: https://www.diariodehuelva.es/2018/09/08/la-procesionextraordinaria-la-virgen-del-rocio-congrega-mas-500-000-personas/ (consulta: 17-10-2019).

[Hermandad Matriz de Almonte], "La Hermandad Matriz pone en valor el compromiso de las Hermandades con la Obra Social del Centenario", 18 de noviembre de 2019. URL: https://hermandadmatrizrocio.org/la-hermandadmatriz-pone-en-valor-el-compromiso-de-las-hermandades-con-la-obra-socialdel-centenario/ (consulta: 24-1-2020).

Aranguren, José Luis (1996), “La religión, hoy”, en R. Díaz Salazar, S. Giner, y F. Velasco (eds.), Formas modernas de religión, Alianza Universidad, Madrid.

Aznar Sala, Javier (2019), "María y el religamiento", en J. PÉrez AdÁn (ed.), Sociología mariana, EUNSA Astrolabio, Pamplona, pp. 89 y ss.

Berger, Peter L. (1999), "The Desecularization of the World: a global overview", en P. P. Berger (ed.), The Desecularization of the World. Resurgent Religion and World Politics, Ethics and Public Policy Center, Washington, D.C.

Bustillo, Víctor C. (2019), "Esta es la oración que se rezará en el centenario de la consagración de España al Sagrado Corazón”, web de la cadena COPE, sección "Iglesia en España", 20 de junio de 2019. URL: https://www.cope. es/religion/actualidad-religiosa/iglesia-en-espana/noticias/esta-oracion-querezara-centenario-consagracion-espana-sagrado-corazon-20190620_441022 (consulta: 15-10-2019).

CANO, Luis (2009), "Reinaré en España”. La mentalidad católica a la llegada de la Segunda República, Ediciones Encuentro, Madrid.

Cueva Merino, Julio (2015), “Conflictiva secularización: sobre sociología, religión e historia", Historia Contemporánea, 51, pp. 365-395.

Cunningham, Lawrence S. (2014), El catolicismo. Una introducción, Akal universitaria, Madrid.

Díaz Pérez, Eva (2011), El polvo del camino. El libro maldito del Rocío, Editorial El Páramo, Córdoba.

García Beltrán, Ginés (2019), Mirar al que traspasaron, Carta pastoral con motivo de la renovación de la Consagración de España al Sagrado Corazón de Jesús, Diócesis de Getafe.

JimÉnEZ, Miguel Ángel, "El Rocío se convierte en pórtico de la gracia de María", $A B C$, edición de Sevilla, 9 de junio de 2019. URL: https://sevilla.abc.es/rocio/ sevi-rocio-2019-rocio-convierte-portico-gracia-maria-201906081210_noticia. html, (consulta: 17-10-2019).

Louzao, Joseba (2008), “La recomposición religiosa en la modernidad: un marco conceptual para comprender el enfrentamiento entre laicidad y confesionalidad en la España Contemporánea", Hispania Sacra, vol. 60, 121, pp. 331-354. 
Louzao, Joseba (2017), “La historia cultural de la religión” en F. Montero García; J. De la Cueva Merino y J. Louzao Villar (eds.), La historia religiosa de la España contemporánea: balance y perspectivas, Universidad, Alcalá de Henares, pp. 279-297.

Murphy, Michael D. y GonzÁlez Faraco, Carlos (2002), "Masificación ritual, identidad local y toponimia en el Rocío", en M. D. Murphy y C. GonzÁLez Faraco (coord.), El Rocío. Análisis culturales e históricos, Diputación Provincial, Huelva.

Murphy, Michael D. y GonzÁlez Faraco, Carlos (2013), “Intensificación cultural en el Rocío. Una aproximación comparada a la devoción rociera", Exvoto, 3, pp. 99-119.

Navarro De La Fuente, Santiago (2014), "La religiosidad popular como elemento de adhesión al primer franquismo. Una aproximación al caso de Sevilla”, en J. L. Ruiz SÁnchez (coord.), La Iglesia en Andalucía durante la Guerra Civil y el primer franquismo, Universidad, Sevilla, pp. 109-126.

Padilla Díaz de la Serna, Santiago (2007), Rocío. La explosión de la gran devoción del sur en el siglo $X X$, Almuzara, Córdoba.

Pérez-Agote, Alfonso (2012), Cambio religioso en España: los avatares de la secularización, Centro de Investigaciones Sociológicas, Madrid.

SÁnchez Arráiz, Rafael, "Día de gloria”, El Correo de Andalucía, 31 de mayo de 1919

SÁnchez GonzÁlez, Martín (2019), Crónica de la renovación de la Consagración de España al Sagrado Corazón de Jesús, Crónica oficial, Getafe. URL: http://www.cronistasoficiales.com/?p=121304 (consulta: 28-10-2019). 